\title{
Effect of pioglitazone tablet administration on liver functions, lipid profile, and antioxidant parameters associated with fatty liver in male sprague-dawley rats
}

Nuriza Ulul Azmi†,

Aleta Violina Purbat,

Asma Fitriani,

Adinda Ayu Rafika Apriliani,

Fadlina Chany Saputri*

Faculty of Pharmacy, University of Indonesia, Depok, Indonesia

*Corresponding author:

Fadlina Chany Saputri

fadlina.chany@farmasi.ui.ac.id

$\uparrow$ Both authors are contributed equally to this work.

\section{KEYWORDS:}

Hospital-acquired pneumonia (HAP); Ventilator-associated pneumonia (VAP); Intensive Care Unit (ICU); Clinical characteristics; Pathogenic bacteria

https://www.pharmacy.mahidol.ac.th/journal/ (C) Faculty of Pharmacy, Mahidol University (Thailand) 2020

\begin{abstract}
Fatty liver is a condition that could develop into nonalcoholic steatohepatitis (NASH) marked by liver inflammation. This condition can be caused by several risk factors such as obesity and dyslipidemia. Previous studies showed that rosiglitazone, one of thiazolidinediones (TZDs), could be used as fatty liver therapy. In this study, pioglitazone, which is also a TZDs, was used to evaluate its effect on liver functions, lipid profile, and antioxidant status in animal models. This research aimed to evaluate the administration of pioglitazone tablets in the animal model. A total of 40 male Sprague-Dawley rats were divided into five groups consisted of normal group, negative control, and three treated groups, which received $5 \mathrm{mg}, 10 \mathrm{mg}$, and $20 \mathrm{mg} / \mathrm{kg} \mathrm{BW} /$ day of pioglitazone tablet. The study was conducted by oral induction of high-fat diet with $0.5 \mathrm{mg} / \mathrm{kg} \mathrm{BW/}$ day propylthiouracil tablet for 70 days. On day 43, pioglitazone tablet was orally administered for 28 days until day 70 . The parameters of liver function, lipid profile, and antioxidant status were measured, and liver morphological was observed. Dose 10 $\mathrm{mg} / \mathrm{kg} \mathrm{BW} /$ day showed the most significant decrease $(\mathrm{p}<0.05)$ of liver function and lipid profile comparing to the animal models. However, pioglitazone tablet at a dose of $20 \mathrm{mg} / \mathrm{kg} \mathrm{BW} /$ day showed a significant decrease $(\mathrm{p}<0.05)$ comparing to both negative control and normal groups. Thus, administration of pioglitazone tablet at a dose of $10 \mathrm{mg} / \mathrm{kg} \mathrm{BW} /$ day possessed an ameliorating effect on the fatty liver condition in male SpragueDawley rats.
\end{abstract}

\section{INTRODUCTION}

Fatty liver is the most common liver disease in the world ${ }^{1}$ with the prevalence of people with the disease in Indonesia at $30 \%{ }^{2}$. The disease is characterized by the accumulation of liver fat that reaches $5 \%$ of the liver weight ${ }^{3}$. This condition can be caused by several risk factors such as obesity, insulin resistance, type 2 diabetes mellitus, dyslipidemia, and drugs ${ }^{4}$. Propylthiouracil (PTU) is an antithyroid drug that has rarely been used because it can cause liver damage and increase blood cholesterol that could trigger the fatty liver disease ${ }^{5}$. A high-fat diet and a high-fructose diet could also cause fatty liver and 
able to develop into non-alcoholic steatohepatitis (NASH), the stage in which inflammation occurs in the liver and leads to the cirrhosis. The percentage of patients with fatty liver that develop into NASH is estimated to reach $10-30 \%$. Moreover, fatty liver is known to be associated with hepatocellular carcinoma and continues to increase every year ${ }^{6}$. Regarding this problem, there is still no specific treatment for fatty liver disease, so it is encouraging the researchers to find complementary and alternative treatments.

Currently, several medications for dyslipidemia and type- 2 diabetes could be alternative drugs for fatty liver disease. Previous studies had shown that rosiglitazone, one of thiazolidinediones (TZDs), could be used as fatty liver therapy ${ }^{7,8}$. On the other hand, rosiglitazone has been reported to increase the risk of heart attack, so the Food and Drug Administration (FDA) restricts the use of the drug ${ }^{9}$. The pioglitazone, which is also a TZDs, is a type 2 antidiabetic drug that works by reducing insulin resistance in the peripheral and liver. Pioglitazone acts as a receptor agonist that activates PPAR- $\gamma$, which can increase the sensitivity of receptors so that glucose can be taken into cells ${ }^{10}$. Besides, pioglitazone can regulate the expression of genes involved in lipid metabolism ${ }^{11}$. Pioglitazone could ameliorate the fatty liver condition. Nevertheless, the understanding of pioglitazone effect on fatty liver conditions is limited. In this study, pioglitazone, which is also a TZDs was used to evaluate its effect on liver functions, lipid profile, and antioxidant status in animal fatty liver models.

\section{MATERIALS AND METHODS}

\subsection{Materials}

The test material used for sample was TZDs agent, Pioglitazone tablet (Actos ${ }^{\circledR}$, Takeda Pharmaceutical, Indonesia) containing $30 \mathrm{mg}$ pioglitazone hydrochloride and formulated with excipients such as lactose monohydrate NF, hydroxypropyl cellulose NF, carboxymethylcellulose calcium NF, and magnesium stearate NF. Induction agents used were propylthiouracil tablet (Dexa, Indonesia) which is containing $100 \mathrm{mg}$ propylthiouracil, high-fat diets containing 36\% fructose (HFCS-55, China), 15\% goat fat, $14 \%$ palm oil (Sunco, Indonesia), and 5\% domestic chicken egg yolk (PT QL Trimitra) and 30\% distilled water in $1.8 \mathrm{~g} / \mathrm{kg} \mathrm{BB}^{12}$.

\subsection{Animals}

This study used 40 male white rats with Sprague-Dawley (SD) strain, aged two months with a weight of 150-250 grams, which were obtained from the Non-Ruminansia and Satwa Harapan Laboratory, Faculty of Animal Husbandry, Institut Pertanian Bogor (IPB), Bogor, Indonesia.

\subsection{Protocol (in vivo)}

The in vivo study was conducted at the Experimental Animal Laboratory, Faculty of Pharmacy, Universitas Indonesia and Pharmacology Laboratory, Faculty of Pharmacy, Universitas Indonesia. This research approved by the Ethics Committee of the Faculty of Medicine, Universitas Indonesia, with protocol number 19-02-0117 was carried out. Before being treated, rats were acclimatized for seven days at the Experimental Animal Laboratory of the Faculty of Pharmacy, Universitas Indonesia, with normal conditions (at room temperature and 12/12-h light/dark cycle). The induction of high-fat diet with $5 \mathrm{mg} / \mathrm{kg} \mathrm{BW} /$ day propylthiouracil tablet was administered orally for 70 days. On day 43, pioglitazone tablet was administered orally and divided into three groups of dose variations $(5 \mathrm{mg} / \mathrm{kg} \mathrm{BW}, 10 \mathrm{mg} / \mathrm{kg} \mathrm{BW}$, and $20 \mathrm{mg} / \mathrm{kg} \mathrm{BW}$ ) until day $70^{13}$.

The study used five test groups consisting of normal groups, which were only given $0.5 \%$ CMC Na solution, the negative control group was a high-fat diet with propylthiouracil tablet and three groups of pioglitazone tablet dose variations. The dosage of pioglitazone tablet used was $5 \mathrm{mg} /$ $\mathrm{kg} \mathrm{BW}, 10 \mathrm{mg} / \mathrm{kg} \mathrm{BW}$, and $20 \mathrm{mg} / \mathrm{kg} \mathrm{BW}$ ).

\subsection{Liver morphology}

On day 70 , rats were dissected to observe changes in morphology of the liver by removing the liver and placed them in a white paper. The number of lumps was observed in five groups to determine the liver function. Furthermore, The blood from the abdominal aorta was collected for the determination of aminotransferase level, lipid profile, and antioxidant status. 


\subsection{Determination of plasma aminotransferase levels}

The blood was centrifuged at $7000 \mathrm{rpm}$ for 15 minutes. Further, plasma was taken and then measured against the enzyme activity of Alanine Aminotransferase (ALT) and Aspartate Aminotransferase (AST). The level of AST was measured by GOT (AST (Aspartate Aminotransferase)) IFCC mod. liquiUV (Human, Germany) while the level of AST using GPT (ALT (Alanine Aminotransferase)) IFCC mod. liquiUV (Human, Germany). The methods were performed according to the kit instructions provided.

\subsection{Determination of plasma lipid profile}

Lipid profiles such as triglyceride levels (TG), high-density lipoprotein (HDL), and total cholesterol (TC) were also determined by colorimetric assay based on the manufacturer's methods using Triglycerides liquicolor ${ }^{\text {mono }}$ kit, HDL Cholesterol kit, and Cholesterol liquicolor kit (Human, Germany). The level of low-density lipoprotein (LDL) was calculated from TG, HDL, and TC values.

\subsection{Determination of plasma antioxidant status}

Superoxide dismutase (SOD) and glutathione peroxidase (Gpx) levels on plasma were measured using Rat SOD2 Superoxidase dismutase [Cu-Zn]) ELISA Kit (FineTest ${ }^{\mathrm{TM}}$, Wuhan, China) according to manufacturer's protocol.

\subsection{Statistical analysis}

The data obtained were processed statistically using SPSS. The analysis carried out was the normality test (Shapiro-Wilk) and homogeneity test (Levene). If it was normally distributed and/or homogeneous, it is evaluated by an independent t-test to see the statistical significance of the differences in the two groups. However, if the data is not normally distributed nor homogeneous, the test used Mann-Whitney analysis. Results were statistically significant if $\mathrm{p}<0.05$.

\section{RESULTS}

\subsection{Effects of pioglitazone tablet administration on aminotransferase activity in plasma}

AST and ALT activities in plasma were measured and shown in Table 1. In this table, all pioglitazone groups showed lower levels compared to the negative control group, while the negative control groups had higher levels compared to the normal group. The pioglitazone group (10 $\mathrm{mg} / \mathrm{kg} \mathrm{BW})$ Dose 2 in both parameters showed a decrease that was lower than the pioglitazone group (20 mg/kg BW).

Table 1. Aminotransferase levels in plasma

\begin{tabular}{cccccc}
\hline Parameter & Normal & Negative Control & PIO Dose 1 & PIO Dose 2 & PIO Dose 3 \\
\hline AST (U/l) & $63.31 \pm 10.99$ & $84.74 \pm 11.42^{*}$ & $62.59 \pm 12.02 \#$ & $45.39 \pm 1.32^{*} \#$ & $78.41 \pm 3.27$ \\
ALT (U/1) & $63.09 \pm 8.78$ & $63.09 \pm 20.66$ & $29.64 \pm 2.93^{*} \#$ & $25.54 \pm 5.24^{*} \#$ & $34.89 \pm 11.03^{*}$ \\
\hline
\end{tabular}

Notes:

Normal: no treatment; negative control: induced by high-fat diet and propylthiouracil tablet; PIO Dose $1: 5 \mathrm{mg} / \mathrm{kg}$ BW/day pioglitazone-treated group; PIO Dose 2: $10 \mathrm{mg} / \mathrm{kg} \mathrm{BW/day} \mathrm{pioglitazone-treated} \mathrm{group;} \mathrm{and} \mathrm{PIO} \mathrm{Dose} \mathrm{3:} 20 \mathrm{mg} / \mathrm{kg}$ BW/day pioglitazone-treated group. AST: aspartate aminotransferase; ALT: alanine aminotransferase. According to independent $\mathrm{t}$ test, $\left(^{*}\right)=\mathrm{p}<0,05$ compared to normal group dan $(\#)=\mathrm{p}<0,05$ compared to negative control group.

\subsection{Effects of pioglitazone tablet administration on lipid profile in plasma}

The lipid profile determined were triglyceride levels (TG), high-density lipoprotein (HDL), low-density lipoprotein (LDL), and total cholesterol (TC). Table 2 showed that the triglycerides levels of all dose groups showed lower values and differed significantly $(\mathrm{p}<0.05)$ compared to the negative control group, and the pioglitazone group $(10 \mathrm{mg} /$ $\mathrm{kg} \mathrm{BW})$ had the lowest value of $94.47 \pm 11.25$ $\mathrm{mg} / \mathrm{dl}$. The same thing happened to both total cholesterol and LDL. All dose groups showed lower values and differed significantly $(\mathrm{p}<0.05)$ on the negative control group. Based on these data, all pioglitazone groups showed values that did not depend on the doses. 
Table 2. Plasma lipid profile

\begin{tabular}{cccccc}
\hline Parameter & Normal & Negative Control & PIO Dose 1 & PIO Dose 2 & PIO Dose 3 \\
\hline TG $(\mathrm{mg} / \mathrm{dl})$ & $96.34 \pm 36.95$ & $167.13 \pm 20.96^{*}$ & $107.61 \pm 18.57 \#$ & $94.47 \pm 11.25 \#$ & $110.66 \pm 30.77 \#$ \\
TC $(\mathrm{mg} / \mathrm{dl})$ & $59.05 \pm 3.89$ & $143.87 \pm 27.16^{*}$ & $69.15 \pm 23.15 \#$ & $50.07 \pm 12.39 \#$ & $44.99 \pm 8.82^{*} \#$ \\
HDL $(\mathrm{mg} / \mathrm{dl})$ & $27.57 \pm 8.74$ & $29.39 \pm 4.25$ & $20.47 \pm 7.27$ & $20.69 \pm 4.68 \#$ & $11.77 \pm 9.08^{*} \#$ \\
LDL $(\mathrm{mg} / \mathrm{dl})$ & $12.22 \pm 4.11$ & $81.06 \pm 20.38^{*}$ & $27.16 \pm 21.07 \#$ & $10.49 \pm 7.82 \#$ & $11.09 \pm 4.75 \#$ \\
\hline
\end{tabular}

Notes:

Normal: no treatment; negative control: induced by high-fat diet and propylthiouracil tablet; PIO Dose 1: $5 \mathrm{mg} / \mathrm{kg}$ BW/day pioglitazone-treated group; PIO Dose 2: $10 \mathrm{mg} / \mathrm{kg} \mathrm{BW/day} \mathrm{pioglitazone-treated} \mathrm{group;} \mathrm{and} \mathrm{PIO} \mathrm{Dose} \mathrm{3:} 20 \mathrm{mg} / \mathrm{kg}$ BW/day pioglitazone-treated group. TG: triglyceride; TC: total cholesterol; HDL: high-density lipoprotein; LDL: low-density lipoprotein. According to independent $t$ test, $\left(^{*}\right)=p<0,05$ compared to normal group dan $(\#)=p<0,05$ compared to negative control group.

\subsection{Effects of pioglitazone tablet administration on antioxidants status in plasma}

In this study, Gpx level in the negative control group was greater than the normal group. The pioglitazone group (10 mg/kg BW) showed the highest antioxidant activity but did not differ significantly $(p>0.05)$ with the other groups. Therefore, no significant data is obtained on Gpx. Conversely, in SOD, the negative control group showed the lowest value. The pioglitazone group ( $5 \mathrm{mg} / \mathrm{kg} \mathrm{BW}$ ) showed the highest value and was significantly different from the negative control and normal group, as seen in Table 3.

Table 3. Antioxidant status in plasma

\begin{tabular}{cccccc}
\hline Parameter & Normal & Negative Control & PIO Dose 1 & PIO Dose 2 & PIO Dose 3 \\
\hline SOD $(\mathrm{ng} / \mathrm{ml})$ & $1.35 \pm 0.57$ & $0.99 \pm 0.20$ & $6.91 \pm 4.73^{*} \#$ & $1.51 \pm 0.94$ & $1.38 \pm 0.37$ \\
Gpx $(\mathrm{pg} / \mathrm{ml})$ & $235.44 \pm 59.02$ & $271.44 \pm 62.23$ & $271.14 \pm 80.10$ & $329.11 \pm 136.66$ & $277.89 \pm 64.36$ \\
\hline
\end{tabular}

Notes:

Normal: no treatment; negative control: induced by high-fat diet and propylthiouracil tablet; PIO Dose 1: $5 \mathrm{mg} / \mathrm{kg}$ BW/day pioglitazone-treated group; PIO Dose 2: $10 \mathrm{mg} / \mathrm{kg}$ BW/day pioglitazone-treated group; and PIO Dose 3: $20 \mathrm{mg} / \mathrm{kg}$ BW/day pioglitazone-treated group. SOD: superoxide dismutase; Gpx: glutathione peroxidase. According to independent $t$ test, $\left({ }^{*}\right)=p<0,05$ compared to normal group dan $(\#)=p<0,05$ compared to negative control group.

\subsection{Effects of pioglitazone tablet administration on liver morphology}

Based on observations of the liver morphology in each group as shown in Figure 1, it could be seen that in all groups induced by a high-fat diet and propylthiouracil tablet showed the white lumps whose numbers differed in each group. The negative control group showed the most amount of lumps compared to other groups.

\section{DISCUSSION}

The presence of fatty liver in patients could be seen from changes in liver function parameters, such as increased levels of Alanine aminotransferase (ALT) and Aspartate Aminotransferase (AST), and decreased Alkaline Phosphatase (ALP) and bilirubin levels. AST and ALT levels in fatty liver conditions were higher than normal liver. In general, the increase in AST and ALT level is closely related to fatty liver. Generally, ALT increases more than AST because ALT is mostly in the cytoplasm, while only $20 \%$ AST is in the cytoplasm with the rest found in mitochondria ${ }^{14}$.

In both AST and ALT levels, the pioglitazone group (10 mg/kg BW) showed a decrease that was lower than the pioglitazone group $(20 \mathrm{mg} / \mathrm{kg}$ $\mathrm{BW}$ ) so that it can be said that this study indicates that pioglitazone tablet was not dose-dependent. However, this might be caused by pioglitazone tablet side effects such as cardiac ${ }^{15}$. Cardiac dysfunction can cause liver damage because both are the most important systemic organs that are interconnected ${ }^{16}$, so that ALT and AST levels were not significantly different from the negative control group or fatty liver model. 


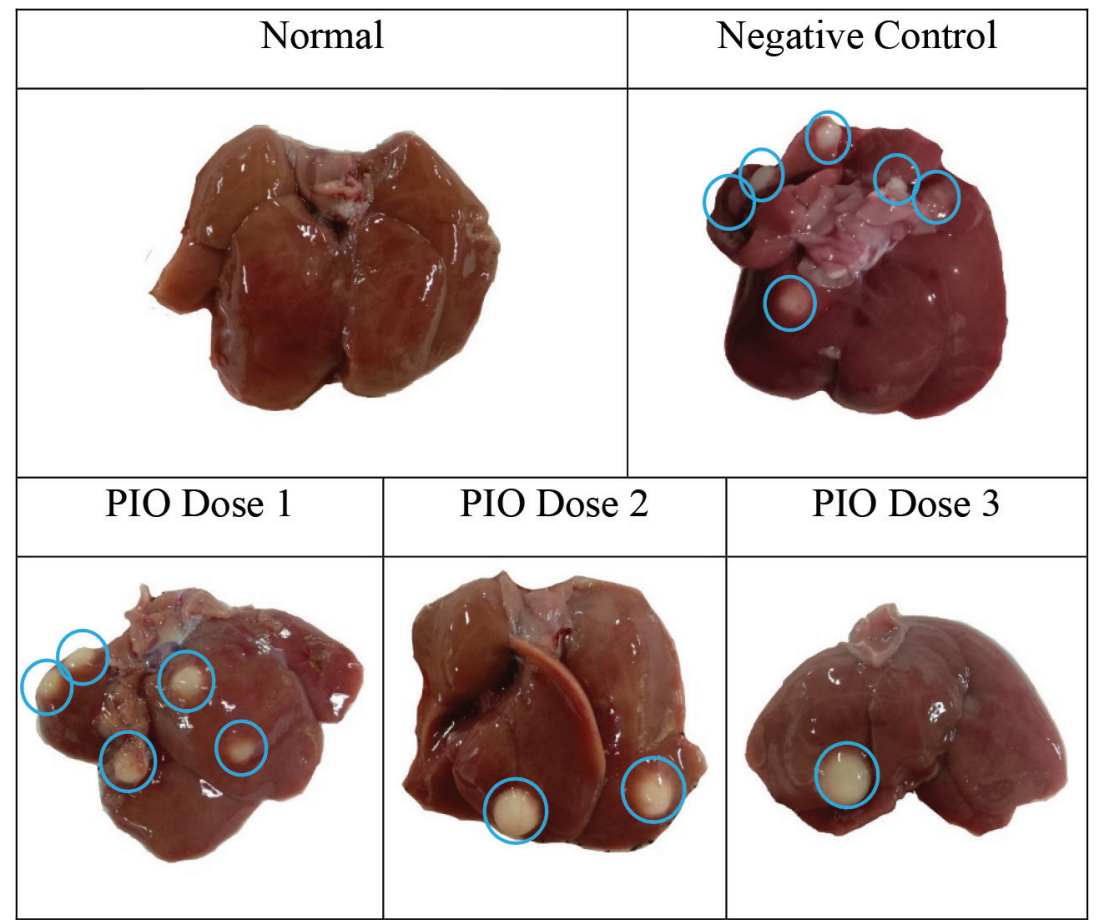

Figure 1. Rat liver morphology of normal, fatty liver, and pioglitazone groups. Normal: no treatment; negative control: induced by high-fat diet and propylthiouracil tablet; PIO Dose 1: $5 \mathrm{mg} / \mathrm{kg}$ BW/day pioglitazone-treated group; PIO Dose 2: $10 \mathrm{mg} / \mathrm{kg}$ BW/day pioglitazone-treated group; and PIO Dose 3: $20 \mathrm{mg} / \mathrm{kg} \mathrm{BW/day} \mathrm{pioglitazone-treated} \mathrm{group.}$

The use of high-fat diet in animal models of fatty liver could cause adipose cells to be unable to accept triglycerides, so triglycerides are broken down or lipolysis into fatty acids that are carried to hepatocyte cells. In hepatocyte cells, fatty acids that could no longer be oxidized are esterified to triglycerides and resulted in the accumulation of triglycerides ${ }^{17}$. Meanwhile, propylthiouracil is working on lowering the thyroid hormone. Thyroid hormones play a role in cholesterol and triglyceride excretion in bile ${ }^{18}$. The decrease in these hormones could increase the chylomicron uptake of cholesterol and triglycerides. Therefore, the combination of high-fat diet and propylthiouracil tablet could obtain animal models of fatty liver.

In the triglyceride parameter, the pioglitazone tablet showed a decrease compared to negative control group. Pioglitazone has been shown to increase the expression of CD36 receptors, fatty acids receptors to the liver so that fatty acids can be oxidized, and blood triglyceride levels decrease ${ }^{11}$. The same thing happened to both total cholesterol and LDL. Besides being able to increase the storage of triglycerides in adipose cells, pioglitazone tablet can bind to LDL receptors so that LDL uptake to cells increases ${ }^{11}$. Increased LDL uptake also increases HDL to bring cholesterol to the liver. It causes a decrease in LDL levels and total cholesterol in plasma while the HDL levels are increased. HDL in fatty liver can reach less than $20 \mathrm{mg} /$ $\mathrm{dl}$, but based on the data in Table 2., all groups are still above $20 \mathrm{mg} / \mathrm{dl}$. Pioglitazone tablet can reduce plasma triglyceride levels up to $14 \%$ and reduce LDL by up to five times ${ }^{19}$.

All pioglitazone groups showed values that did not depend on the dosage because the pioglitazone group $(10 \mathrm{mg} / \mathrm{kg} \mathrm{BW})$ showed the best fatty liver repair condition compared to the pioglitazone group (20 mg/kg BW). The pioglitazone group (10 mg/kg BW) indicated the most optimal dose. The pioglitazone group (20 mg/kg BW), which was two times more than the pioglitazone group (10 mg/kg BW) might have been cause side effects such as a decrease in cholesterol and HDL so that the pioglitazone group $(20 \mathrm{mg} / \mathrm{kg} \mathrm{BW})$ showed a significantly $(p<0.05)$ different value from the normal group. Research conducted by Spainhamer et al. showed that pioglitazone tablet 
increased HDL levels significantly $(p<0.05)$ while in this study, HDL decreased. It can be caused by a decrease in total cholesterol, causing HDL not to be able to deliver excess total cholesterol from the tissue to be returned to the liver so that HDL in the blood is low ${ }^{20}$.

In fatty liver disease, a decrease in lipid oxidation can cause oxidative stress, which is a condition where oxidants and antioxidants are unbalanced, resulting in a reduction of endogenous antioxidants such as Gpx and SOD is prone to occur $^{21}$. In this study, Gpx in the negative control group was higher than the normal group. It is probably caused by fatty liver disease that has not developed into NASH. Oxidative stress conditions have not provided a sign of inflammation resulting in the antioxidants have not been disturbed. In addition, the pioglitazone group (10 mg/kg BW) showed the highest antioxidant activity but did not differ significantly $(p>0.05)$ with the other groups. Antioxidants greatly contribute to the improvement of mitochondrial dysfunction, so if there is no damage to the mitochondria, the antioxidants have not worked significantly. Based on observations of liver morphology, lumps could probably have been used as a marker that showed the liver was abnormal. As mentioned in all parameters, dosage is very influential because all doses showed values that are different. The pioglitazone group $(10 \mathrm{mg} / \mathrm{kg} \mathrm{BW})$ showed a significant difference $(p<0.05)$ compared to the negative control group.

\section{CONCLUSIONS}

Pioglitazone tablet has an effect on changes in liver function in fatty liver animal models induced by high-fat diet and propylthiouracil tablet by showing a significant difference $(p<0.05)$ in AST, ALT, TG, TC, HDL and LDL parameters. The dosage of $10 \mathrm{mg} / \mathrm{kg} \mathrm{BW} /$ day pioglitazone showed the most significant difference $(\mathrm{p}<0.05)$ on animal fatty liver models compared to other doses. Pioglitazone tablet also lowering the number of lumps in liver of animal models of fatty liver. Further study is needed to investigate the specific pathway intervention of pioglitazone on the celullar response using hepatocytes.

\section{ACKNOWLEDGMENTS}

This research was supported by Faculty of Pharmacy and funded by Directorate Research and Community Engagement Universitas Indonesia.

\section{Conflict of interest}

No conflict of interest to disclosure

\section{Funding}

None to declare

\section{Ethical approval}

Must be declare

\section{Article info:}

Received December 16, 2019

Received in revised form February 28, 2020

Accepted March 26, 2020

\section{REFERENCES}

1. Younossi ZM. The epidemiology of nonalcoholic steatohepatitis. Clin Liver Dis. 2018;11 (4):92-4.

2. Moghaddasifar I, Lankarani KB, Moosazadeh M, Afshari M, Ghaemi A, Aliramezany M, et al. Prevalence of nonalcoholic fatty liver disease and its related factors in Iran. Int J Organ Transplant Med. 2016;7(3):149-60.

3. Nassir F, Ibdah JA. Role of mitochondria in nonalcoholic fatty liver disease. Int J Mol Sci. 2015;15(5):8713-42.

4. Kumar V, Abbas AK, Aster JC, Robbins SL. Robbins basic pathology. Philadelphia: Elsevier/ Saunders;2013.

5. LiverTox: Clinical and research information on drug-induced liver injury [document on the Internet]. Bethesda: National Institute of Diabetes and Digestive and Kidney Diseases; 2012. Propylthiouracil. [Updated 2020 Feb 10]. Available from: https://www.ncbi.nlm.nih.gov/ books/NBK547973/

6. Zaki AS. The rise in the prevalence of nonalcoholic fatty liver disease and hepatocellular carcinoma. In: Gad EH, editor. Nonalcoholic fatty liver disease - An update [document on the internet]. IntechOpen; 2019. DOI: 10.5772/ intechopen.85780. Available from: https:// www.intechopen.com/books/nonalcoholicfatty-liver-disease-an-update/the-rise-in-theprevalence-of-nonalcoholic-fatty-liver-diseaseand-hepatocellular-carcinoma

7. Ratziu V, Charlotte F, Bernhardt C, Giral P, Halbron M, Lenaour G, et al. Long-term efficacy 
of rosiglitazone in nonalcoholic steatohepatitis: results of the fatty liver improvement by rosiglitazone therapy (FLIRT 2) extension trial. Hepatology. 2010;51(2):445-53.

8. Torres DM, Jones FJ, Shaw JC, Williams CD, Ward JA, Harrison SA. Rosiglitazone versus rosiglitazone and metformin versus rosiglitazone and losartan in the treatment of nonalcoholic steatohepatitis in humans: a 12-month randomized, prospective, open- label trial. Hepatology. 2011;54(5):1631-9.

9. Tanne JH. FDA committees say keep rosiglitazone available but increase warnings. BMJ. 2007; 335(7613):223. doi:10.1136/bmj.39294. 417442.DB

10. Berger J, Moller DE. The mechanisms of action of PPARs. Annu Rev Med. 2002; 53 : 409-35.

11. Cariou B, Charbonnel B, Staels B. Thiazolidinediones and PPAR $\gamma$ agonists: Time for a reassessment. Trends Endocrinol Metab. 2012;23(5):205-15. https://doi.org/10.1016/ j.tem.2012.03.001

12. Nugroho AE, Andrie M, Warditiani NK, Siswanto E, Pramono S. Antidiabetic and antihiperlipidemic effect of Andrographis paniculata (Burm. f.) Nees and andrographolide in high-fructose-fat-fed rats. Indian J Pharmacol. 2012;44(3):377-82.

13. Mushollaeni W, Supartini N, Rusdiana E. Decreasing blood cholesterol levels in rats induced by alginate of Sargassum duplicatum and Turbinaria sp. derived from Yogyakarta. Asian J Agric Food Sci. 2015;3(4):321-6.

14. Chang WJ, Joe KT, Park HY, Jeong JD, Lee DH. The relationship of liver function tests to mixed exposure to lead and organic solvents. Ann Occup Environ Med. 2013;25(1):5. https:// doi.org/10.1186/2052-4374-25-5
15. Takeda America Research and Development Center, I. ACTOS (pioglitazone hydrochloride) tablets [document on the internet]. Takeda Chemical Industries; 1999: NDA No. 21-073: (21):1-26. Available from https://www. accessdata.fda.gov/drugsatfda_docs/label/ 1999/21073lbl.pdf

16. Xanthopoulos A, Starling RC, Kitai T, Triposkiadis F. Heart failure and liver disease: cardiohepatic interactions. JACC Heart Fail. 2019;7(2):87-97.

17. Scherer DJ, Nicholls SJ. Lowering triglycerides to modify cardiovascular risk: will icosapent deliver? Vasc Health Risk Manag. 2015;11: 203-9.

18. Duntas LH, Brenta G. A renewed focus on the association between thyroid hormones and lipid metabolism. Front Endocrinol (Lausanne). 2018;3(9):511.

19. Kendall D, Rubin C, Mohideen P, Ledeine JM, Belder R, Gross J, Norwood P. Improvement of glycemic control, triglycerides, and HDL cholesterol levels receptor activator, in patients with type 2 diabetes inadequately controlled with metformin monotherapy. Diabetes Care. 2006;29(5):1016-25.

20. Spanheimer R, Betteridge DJ, Tan MH, Ferrannini E. Long-term lipid effects of pioglitazone by baseline anti-hyperglycemia medication therapy and statin use from the PROactive experience (PROactive 14) macrovascular events (PROactive) to determine whether pioglitazone-induced lipid effects. Am J Cardiol. 2009;104(2):234-9.

21. Wu PJ, Chen JB, Lee WC, Ng HY, Lien SC, Tsai PY, et al. Oxidative stress and nonalcoholic fatty liver disease in hemodialysis patients. Biomed Res Int. 2018;2018:1-7. https://doi. org/10.1155/2018/3961748. 